\title{
No driving for Miss Daisy
}

$\mathrm{T}$ he rising use of computerized testing to determine whether people are medically fit to drive is causing a stir in the Canadian seniors community - and raising questions about the effectiveness of current methods of assessment.

Moreover, a popular mechanism for testing seniors, a computer program known as DriveABLE that is used in seven provinces and territories, is biased against seniors, says Carol Libman, advocacy consultant for the Canadian Association of Retired Persons (CARP).

Libman says the association has received numerous complaints from seniors frustrated with their experiences with DriveABLE, which is used in Ontario, Quebec, Nova Scotia, British Columbia, Manitoba, Alberta and the Yukon Territory (www.driveable.com /index.php/contact-diriveable/canadian -locations). "They find that this thing is really intimidating," she says, "and not a fair test of cognitive ability, or driving ability."

Although widely used, programs like DriveABLE should not be the sole determinant of a senior's capacity to drive, says Dr. Malcolm Man-Son-Hing, a geriatrician at the Ottawa Hospital in Ontario. "It can give some indication," he says. But "you can't hang your hat on any single test out there."

"It's really a clinical judgment," Hing adds. "Who else is in a better position to make that call than their physician?"

But Drive ABLE developer Allen Dobbs rejects the notion that the program is biased against seniors. Dobbs says results from the computerized portion of the test reflect the individual's level of cognitive ability, not their age.

"It's not age. It really is [based on] the medical condition," Dobbs says. "Granted, the older you get, the more likely you are to have one of those medical conditions, but it really is the condition."

Libman, though, says many seniors complain they are disadvantaged because the "DriveABLE Cognitive Assessment Tool" test uses unfamiliar touch-screen technology. Put an eightyear-old in front of the computer and it's possible they could pass the test.
But that doesn't mean the child is fit for the roads. "As far as we are concerned, it is being relied on too heavily as a test for safe driving," Libman says, adding that everyone who takes the cognitive portion - pass or fail — should be allowed to take a road test.

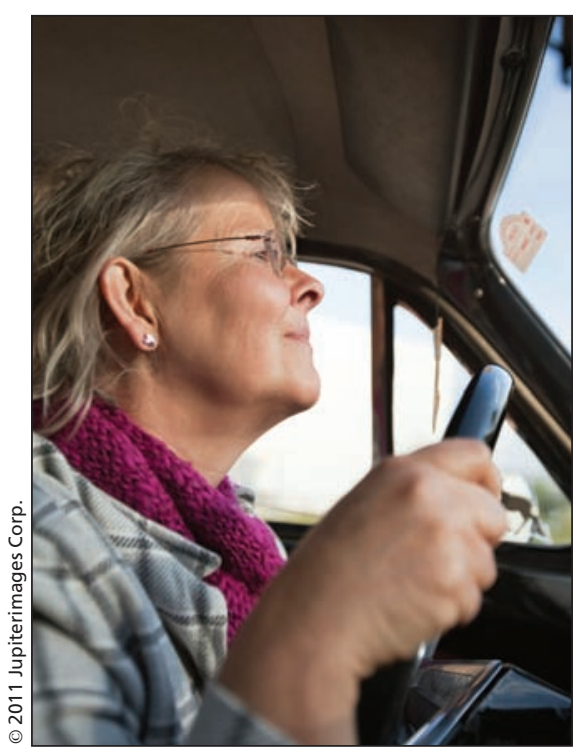

Experts say there's no scientific standard for determining whether a senior citizen can still drive safely, but medical red flags include moderate to severe dementia, drug use impairing cognitive and/or motor function, and multiple physical deficits that combine to reduce the patient's driving ability.

DriveABLE is software that its marketers claim can judge, based on an inoffice computer test and, if necessary, an on-road test, whether an individual is fit to drive (www.driveable.com/index .php/about-driveable). The test was developed over the course of eight years by Dobbs, then the director of the neurocognitive research unit within the Northern Alberta Regional Geriatric Program, and colleagues. Results form the basis of recommendations on whether to revoke a person's licence. Doctors and, in some cases, licensing authorities, refer those they feel are at risk to a DriveABLE office for testing, says Dobbs.

"People who can no longer drive safely are sick," says Dobbs. "Most often, they have some type of progressive illness, which means that not being able to drive is just one of the many losses the person is going to suffer."
According to a demonstration video on the DriveABLE website (www.drive able.com/index.php/videos/63-videos/144 -demo-video.html), an individual is asked to complete a series of tasks designed to test basic cognitive functions like motor speed and control, spatial judgment and decision making, as well as the speed of attention shifting.

The test scores are analyzed by the DriveABLE server, which issues a report outlining a person's score and the probability that he would fail a road test. If a person falls below a certain line, he's deemed unfit for the road. If he scores higher than a certain marker, he passes the cognitive portion. In both cases, a road test is deemed unnecessary.

But those whose scores fall between these two points are required to complete a driving test, administered by a DriveABLE instructor, Dobbs says.

How do these tests measure up against a traditional physician's assessment?

Hing and a colleague, Dr. Shawn Marshall of the Ottawa Hospital Rehabilitation Centre, are conducting a fiveyear study of senior Canadian drivers (www.cihr-irsc.gc.ca/e/39178.html), in which they are taking 1000 subjects older than age 70 and annually evaluating their medical, psychological and functional health. Their vehicles are also outfitted with global positioning systems that will allow Hing and Marshall to analyze their driving habits.

"Some of them will crash in the next five years, and some of them won't," Hing says, adding that the goal is to create a standardized test that will take the guesswork out for doctors as to whether a patient is safe for the roads.

In 7 of 10 provinces, as well as all 3 territories, physicians are legally obligated to report patients they feel are medically unfit to drive to licensing authorities (www.cma.ca/multimedia/CMA /Content_Images/Inside_cma/WhatWe Publish/Drivers_Guide/Section03_e .pdf). Failure to do so could subject the physician to liability if a patient is subsequently involved in an accident. In Nova Scotia, Quebec and Alberta, doctors are given discretion as to whether to report a patient's fitness to drive.

In making a determination, Hing 
takes into account recent accidents, as well as direct information from a patient's family, such as whether they would feel safe if their child was a passenger in a car driven by the patient.

Medical red flags include moderate to severe dementia, drug use and multiple physical deficits that combine to reduce the patient's driving ability (www.cma.ca/multimedia/CMA/Content _Images/Inside_cma/WhatWePublish /Drivers_Guide/Section07_e.pdf).

The problem is that there's no scientific standard for making the call, Hing says. Some doctors are too strict and others, too lenient. "That kind of variation in practice is rather unfair. ... It puts a huge strain on the physician-patient relationship.'

Creating a scientifically sound and easy-to-use test will lessen physician reliance on factors like age in making that determination, Hing adds. "Age in itself is not a good criterion to determine whether older persons are fit to drive." - Jennie Russell, Ottawa, Ont.

CMAJ 2011. DOI:10.1503/cmaj.109-3822

\section{More news at www.cmaj.ca}

Tracking infectious diseases in cyberspace: A Web-based, open-access system has been created to provide real-time intelligence about emerging infectious diseases. - Adrianna Banaszek, Ottawa, Ont.

The secret's in: Open data is a foreign concept in Canada: The systemic secrecy in which Health Canada shrouds data is "outdated" and "embarrassing" in comparison with the openness of other countries in delivering data to citizens, say public health advocates. — Lauren Vogel, CMAJ

Opening the gates on US government data: Open government initiatives can be a boon to public health research and patient-centred care but realizing the maximum benefit of such initiatives requires more than just dumping data online, say American policy wonks. — Lauren Vogel, CMAJ

Nunavut government assailed over outbreak: The government of Nunavut is "covering up" information indicating that a wave of flu-like illness that is sweeping Nunavut's communities in recent weeks is actually an epidemic of respiratory syncytial virus, a Canadian infectious diseases expert charges. - Paul Christopher Webster, Toronto, Ont.

Unproven Olympic health legacies: British couch potatoes are not trading their TV remotes for running shoes as quickly as organizers of the 2012 London Olympic Games had hoped. - Roger Collier, CMAJ

Federal government unveils modest transparency initiative: Canada has dipped a toe into the waters of transparency that are sweeping through other nations by unveiling a tentative three-part plan to modestly improve citizen access to data. — Lauren Vogel, CMAJ

Shedding light on retractions: A new blog is peeking into the dark corners where medical journals stash their retractions and hoping to drag that information out into the light. - Roger Collier, CMAJ

French boost European telemedicine: French doctors will be entitled to bill the government for some medical services provided over the phone under legislation aimed at redressing regional inequities. - Ana Luísa Neves MD, Paris, France, and Tiago Villanueva MD, Lisbon, Portugal

CMAJ 2011. DOI:10.1503/cmaj.109-3848 cmaj.ca

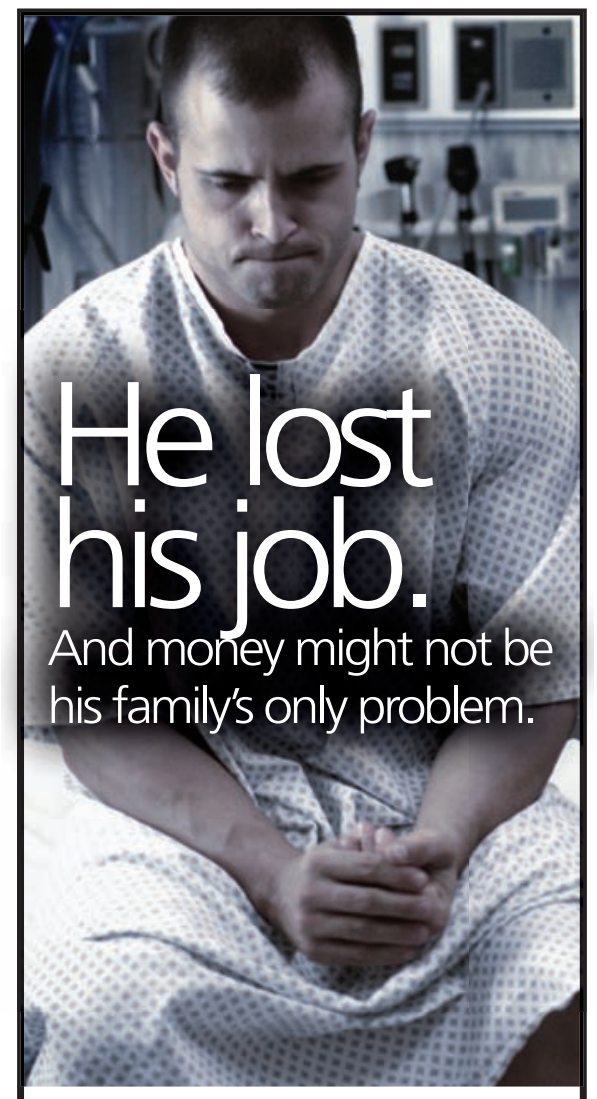

For some men, unemployment can trigger domestic violence or even femicide.

Studies have shown that unemployment and depression are key risk factors for domestic violence, femicide and femicidesuicide. What's more, prior domestic violence and actual or impending separation increase the risk. And that's not all. Stalking and harassment are also strongly associated with lethal violence.

In most cases of intimate femicide, there is a history of partner violence. As family physicians, you can help. There are ways to recognize when your patient may be abusive. There are things you can do and say. And there are ways to respond when both he and his partner are your patients.

You can learn more about domestic violence and, at the same time, earn valuable CME credits from the Royal College of Physicians and Surgeons of Canada and the College of Family Physicians of Canada.

Visit us on-line at www.DVeducation.ca

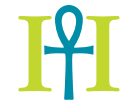

WOMEN'S COLLEGE HOSPITAL Health care for women REVOLUTIONIZED 